\title{
A VARIAÇÃO DENOMINATIVA NA TERMINOLOGIA DA FAUNA E DA FLORA: (AS)SIMETRIAS LINGUÍSTICO- CULTURAIS
}

\author{
Sabrina de Cássia Martins \\ Universidade Estadual Paulista Júlio de Mesquita Filho \\ São José do Rio Preto, São Paulo, Brasil
}

\begin{abstract}
Resumo: O presente estudo abrange o tema da variação denominativa em Terminologia, tendo como objeto de estudo as unidades lexicais especializadas formadas pelos nomes de cores preto, branco, amarelo, azul, laranja, cinza, verde, marrom, vermelho, rosa, violeta, roxo e anil em língua portuguesa e seus respectivos correspondentes em inglês e italiano. Limitamo-nos a duas subáreas da Biologia: a Botânica, especificamente as Angiospermas (monocotiledôneas e eudicotiledôneas), e a Zoologia, exclusivamente os Vertebrados (peixes, mamíferos, aves, anfíbios e répteis). Uma vez sabido que a variação denominativa tem presença marcante na terminologia desses domínios em língua portuguesa, descreveremos o modo como ocorre a (não) correspondência entre os nomes comuns das espécies nas línguas em questão.
\end{abstract}

Palavras-chave: Terminologia; Variação denominativa; Fauna e flora; Nomes de cores

\section{DENOMINATIVE VARIATION IN THE TERMINOLOGY OF FAUNA AND FLORA: CULTURAL AND LINGUISTIC (A)SYMMETRIES}

\begin{abstract}
The present work approaches the denominative variation in Terminology. In this way, it has as object of study the specialized lexical units in Portuguese language formed by at least one of the following color names: black, white, yellow, blue, orange, gray, green, brown, red, pink, violet, purple and indigo. The comparative analysis
\end{abstract}


of this vocabulary among Portuguese, English and Italian languages was conducted considering two sub-areas of Biology: Botany, specifically Angiosperms (Monocotyledons and Eudicotyledons), and Zoology, exclusively Vertebrates (fish, amphibians, reptiles, birds and mammals). It will be described in the next pages how common names are created in these tree languages.

Keywords: Terminology; Denominative variation; Fauna and flora; Color names.

\title{
Introdução
}

Ao afirmar que se trata do acervo cultural de um povo, Biderman (2001) destaca o poder do léxico de uma língua, pois é nesse nível de análise em que as características culturais estão mais arraigadas e que as diferenças mais se sobressaem. Sem dúvida, é por meio do léxico que ordenamos, identificamos as semelhanças e as diferenças e estruturamos o mundo à nossa volta. Essa atividade de nomear origina-se do processo de categorização, fundamentado

\begin{abstract}
(...) na capacidade de discriminação de traços distintivos entre os referentes percebidos ou apreendidos pelo aparato sensitivo e cognitivo do homem. A esse processo segue-se $o$ ato de nomear. Por essa razão a categorização é o processo em que se baseia a semântica de uma língua natural, por meio do qual o homem desenvolveu a capacidade de associar palavras a conceitos (BIDERMAN, 2006, p. 35).
\end{abstract}

Por conseguinte, é mediante a categorização que uma sociedade realiza o registro do conhecimento, nomeando culturalmente os conceitos que expressam sua evolução no decorrer do tempo. Explica-se, assim, a a relação entre a formação das terminologias com a cultura da sociedade que as utiliza, pois, segundo Silva Filho (2010), o termo nada mais é do que a reflexão da forma como os especialistas veem o mundo, interpretação que depende, 
em primeiro lugar, da capacidade físico-cognitiva do ser humano em captar e processar os estímulos externos aos quais é submetido; em segundo, das diferenças de sentir, perceber, pensar e refletir sobre a realidade.

Nesse contexto, cabe destacar o uso de campos léxicos bem estruturados, tais como aquele composto por nomes de cores, para a formação de termos complexos. Efetivamente, o ser humano tem por natureza a sensibilidade que torna possível a percepção visual das ondas eletromagnéticas em que se localizam as cores básicas. Contudo, o caminho percorrido desde a percepção visual até a expressão linguística é variável entre as línguas, resultando em fragmentações divergentes do espectro cromático. Ademais, origina uma riqueza lexical de proporções distintas, fruto do emprego que uma dada comunidade faz dos nomes de cores. Sem dúvida, como afirma Zavaglia (2006, p.26), “(...) o homem foi criando e registrando linguisticamente sua afetividade pelas cores (...) exprimindo suas emoções por meio de cromônimos - hoje tão incorporados à sua realidade". É esse uso inconsciente e tão assíduo das cores para descrever a relação do homem com o mundo que resulta no emprego dos nomes de cores para a denominação de processos, substâncias, pigmentos, fatos sociais e, em especial, animais e plantas (MARTINS; ZAVAGLIA, 2012).

No que concerne especificamente a esses dois últimos grupos, Garrido (2000) salienta que, na terminologia da Botânica e da Zoologia, coexistem: i) os nomes científicos, ii) as formas semicientíficas, adaptadas à língua vernácula e iii) as formas vernáculas, isto é, nomes comuns variáveis no que tange à motivação e ao número, de acordo com as línguas. Decerto, o surgimento dos nomes comuns provém da adequação do discurso à situação comunicacional em que é proferido, bem como ao grau de conhecimento de seus interlocutores. Cada um desses nomes sublinha uma característica distintiva da espécie que propicia sua identificação imediata quando comparada com outras entidades de uma mesma família. Sem dúvida, uma riqueza vocabular que, no âmago dos estudos terminólogicos, resulta do fenômeno da variação denominativa. 
É no interior do conjunto lexical composto pelos nomes populares das espécies de Angiospermas e de Vertebrados que se situa o nosso objeto de estudo, a saber, as expressões cromáticas especializadas (doravante ECEs), isto é, unidades lexicais simples ou complexas, sendo nesse último caso caracterizadas por uma estrutura sintagmática nominal, cuja composição envolve a presença de um ou mais nomes de cores pertencentes aos subdomínios cromáticos preto, branco, amarelo, azul, laranja, cinza, verde, marrom, vermelho, rosa, violeta, roxo e anil, tipologia esta que segue as propostas de Berlin e Kay (1969), Arcaini (1991) e Zavaglia (1996). Efetivamente, a cor é uma característica distintiva no campo da Fauna e da Flora, possibilitando a identificação imediata da espécie, o que explica o uso frequente dos nomes de cores na formação de seus nomes comuns.

Ao longo dos últimos anos, temos investigado comparativamente a formação dessa terminologia entre as línguas portuguesa, inglesa e italiana. Comprovamos em Martins (2013) a atuação das ECEs como mediadoras entre o discurso comum e o especializado em língua portuguesa, bem como o alto índice de variação nesse campo na mesma língua. Além disso, elaboramos um dicionário especializado cuja macroestrutura inclui cerca de duzentas ECEs presentes nesses domínios. O presente trabalho deriva de nossa pesquisa de doutorado (MARTINS, 2017) e objetiva descrever a (não) correspondência entre os nomes comuns nas línguas em questão, atentando para a forma como os traços distintivos das espécies mostram-se ou não evidentes em cada uma das línguas, além de observar as (as)simetrias linguístico-culturais quando diante da presença de correspondentes. Antes, porém, discutimos brevemente sobre a abordagem teórica que fundamenta nosso estudo. 


\section{O fenômeno da variação em Terminologia e seu impacto na tradução especializada}

Entendida como uma prática social, o objetivo principal do ato tradutório encontra-se na mediação entre culturas sem que para tanto a pluralidade, a identidade e a ideologia de cada povo sejam anuladas. Ao contrário do que se espera, a tradução especializada não é de forma alguma uma prática culturalmente neutra, já que, para além da simples transferência de sentidos, ou da transmissão de conceitos, envolve um processo de comunicação. Uma vez que a tradução assume o papel de disseminar o conhecimento técnico e científico através das barreiras culturais e, entendendo que a comunicação, o discurso e os textos especializados apresentam particularidades que apontam inclusive para o seu grau de especificidade, torna-se evidente a relação de complementaridade entre a Terminologia e a Tradução. De acordo com Cabré (2004), a terminologia é responsável por expressar adequadamente o conhecimento especializado, auxiliando na tarefa do tradutor. Adequadamente, adequar, adequado, adequação. Palavras que, a princípio, podem remeter o leitor a uma visão tradicional de tradução ou terminologia, mas que para nós indica não apenas uma concepção de língua como um fenômeno social complexo, como também uma revisão teórica no âmbito dos estudos da linguagem.

No que tange aos estudos terminológicos, se outrora a Teoria Geral da Terminologia pregava o caráter biunívoco na relação entre termo e conceito, refutando, para tanto, toda e qualquer forma de variação, a virada do século traz à tona o seu reflorescimento com uma nova concepção do próprio objeto da Terminologia e do que vem a ser a comunicação especializada. Dentre os vieses teóricos emergentes nesse período, a Teoria Comunicativa da Terminologia - TCT (CABRÉ, 1999) emerge como uma abordagem linguística inovadora para a análise das terminologias, defendendo uma visão integradora entre os recursos linguísticos e extralinguísticos e uma mudança de foco para os discursos que envolvem a comunicação especializada. Como bem salienta Cabré (1999), a TCT leva em 
conta as dimensões textual e discursiva dos termos, por isso toma como pressuposto a diversificação resultante dos fatores extralinguísticos que atuam na comunicação.

O princípio da variação em terminologia é um dos elementos que fundamentam a TCT, sendo uma das condições inerentes ao estudo das unidades lexicais especializadas (ULEs), já que a variação é um traço próprio da comunicação, embora possa se manifestar em diferentes graus, segundo a situação comunicativa (CABRÉ, 1999). De fato, o conhecimento especializado se concentra nas ULEs, cujo teor conceitual pode variar segundo o propósito do texto em que ocorre (CABRÉ, 2002). Logo, a variação constata-se desde seu grau mínimo, próprio da terminologia normatizada por comissões de especialistas, até o seu grau máximo, como ocorre com as terminologias utilizadas nos discursos de divulgação da ciência e da tecnologia. Por essa razão, a TCT sustenta que a densidade cognitiva de um texto é diretamente proporcional à sua quantidade terminológica e ao seu grau de compreensão estrutural e textual, afirmação que remete ao princípio de 'valor terminológico’ das ULEs e do grau de especialização de seu conteúdo conceitual, segundo o qual

[...] um termo não é uma unidade em si mesma, mas apenas um valor associado a todas as unidades do léxico, de modo que cada uma delas não é por si mesma, como afirmamos, nem termo nem palavra, mas sim ativa ou não seu valor de termo em função de seu uso particular em um contexto comunicativo determinado. Essa proposta, denominada "Princípio do valor terminológico", constitui um dos pilares sobre os quais se sustenta nossa proposta teórica (CABRÉ, 2008, p. 18, tradução nossa).

Uma vez que a TCT parte da concepção do termo como uma unidade lexical que assume tal estatuto devido às condições pragmáticas envolvidas em um determinado tipo de comunicação, compreende-se que as unidades lexicais presentes em nossos discursos 
diários e as ULEs apenas podem ser distinguidas pelo valor especializado que os discursos configuram ao item e que o transforma em uma unidade de conhecimento especializado. É justamente esse valor que, além de atribuir aos textos o caráter de especializado, possibilita a harmonização entre os diferentes níveis de língua, os diferentes níveis de conhecimento dos falantes e, consequentemente, o grau de especialização da manifestação discursiva.

Segundo Freixa (2005), no âmbito da tradução especializada, a variação terminológica é um dos obstáculos que o tradutor precisa estar preparado para identificar e solucionar. Do exposto anteriormente, compreende-se que a variação é inerente à terminologia, exprimindo, por um lado, as distinções em se apreender um mesmo conceito; por outro, as diferentes formas de categorizá-lo e empregar tal categorização na comunicação. Por conseguinte, aceitar a existência de variantes em terminologia implica reconhecer que o discurso especializado é dinâmico e que está sujeito a todas as influências sócio-históricas e culturais dispostas pela sociedade que o emprega. Mais ainda, implica no reconhecimento de que a relatividade configurada à categorização da realidade e à sua expressão na linguagem também se manifestam nas terminologias.

A variação terminológica pode ser encontrada em planos distintos, dividindo-se em: i) variação originada de heterogeneidades no plano do conteúdo, a chamada variação conceitual, e ii) variação localizada no plano das denominações, a chamada variação denominativa (FREIXA et al., 2002). Para este estudo, interessa-nos apenas o segundo tipo, definido por Freixa (2002) como a existência de diversas denominações para um mesmo conceito. Para Bach e Suárez (2002), trata-se de um fenômeno frequente nos textos especializados, podendo se apresentar entre unidades simples ou sintagmáticas, representando um conjunto de elementos que estabelecem uma relação de sinonímia em diversos graus. Ciapuscio (2003), por sua vez, enfatiza que a variação denominativa resulta da variação dos graus de especialização dos textos e da diferença de conhecimento entre os seus destinatários. 
A análise comparativa entre nomes populares em português das 92 espécies de Vertebrados e 75 espécies de Angiospermas constantes no Dicionário onomasiológico de expressões cromáticas da fauna e da flora (MARTINS, 2013), e seus respectivos correspondentes em inglês e italiano permitiu-nos concluir que a variação denominativa na terminologia da Fauna e da Flora origina-se das diferentes perspectivas sobre as quais uma mesma espécie pode ser notada, o que resulta na maleabilidade de sua denominação. Em outras palavras, são os diferentes pontos de vista sobre uma mesma espécie que estimulam a variação denominativa na terminologia em questão. Como ponderado por Cabré (2008), contextos distintos ocasionam necessidades distintas que fazem com que um indivíduo perceba determinados fenômenos ou traços peculiares que outros indivíduos, em contextos diversos, talvez não percebam. Ademais, a muldimensionalidade, a variabilidade e a flexibilidade configuradas aos conceitos e às estruturas conceituais se refletem em sua denominação e se manifestam na forma de variantes denominativas. Assim, embora cada espécie seja denominada por um nome científico, que a identifica no interior de um táxon, também é denominada por nomes comuns que evidenciam suas características mais proeminentes, tais como o lugar onde é encontrada, suas características físicas, seus benefícios ou malefícios para o ser humano, entre outras, podendo a motivação da denominação transcender as línguas e culturas. A seguir, relatamos as diferenças e similitudes no modo como as línguas portuguesa, inglesa e italiana denominam popularmente as espécies abrangidas no nosso estudo.

\section{(As)simetrias linguístico-culturais na formação dos nomes comuns das espécies da fauna e da flora em português, inglês e italiano}

Entendendo que a percepção visual é uma habilidade universal do ser humano, é muito provável que as características mais evidentes a olho nu sejam linguisticamente representadas por di- 
ferentes povos. Visto que o espectro cromático está refletido na natureza, explica-se o uso dos nomes de cores na denominação das espécies nas mais variadas línguas. Entretanto, muitas vezes uma mesma realidade é formalmente expressa de modo distinto de comunidade para comunidade. Se realizarmos uma análise comparativa entre as línguas portuguesa, inglesa e italiana, considerando em português não apenas as ECEs, mas todas os nomes populares de cada espécie abordada no dicionário acima mencionado, chegamos a uma tipologia de casos de (não) correspondência.

Importa clarificar que a busca dos correspondentes das cerca de duzentas palavras-entrada presentes no dicionário acima mencionado foi realizada exclusivamente pela Web, sendo utilizados os buscadores o Google.com e o Google.it, em que foram inseridos o nome científico mais atual da espécie. Desse modo, a Web não apenas nos possibilitou encontrar os correspondentes dos nomes populares das espécies consideradas, como também nos permitiu validar o seu uso. Isso posto, observemos, primeiramente, os dados obtidos em língua inglesa:

i) Para espécies denominadas em português por uma única unidade especializada composta por um nome de cor:

a. A correspondência se dá por meio de uma denominação comum formada por um nome de cor que expressa a mesma realidade cromática, p.ex.,

Euterpe oleracea Mart. açaí-branco white açaí

b. Ocorre a variação denominativa em inglês com a presença de uma unidade composta por um nome de cor que expressa a mesma realidade cromática, p.ex.,

Iguana iguana iguana-verde green iguana/common

(L., 1758) iguana 
c. Ocorre a variação denominativa em inglês com a presença de uma unidade formada por um nome de cor que expressa uma realidade cromática diferente, p.ex.,

Curcuma roscoeana Wall. açafrão-vermelho orange ginger e orange hidden ginger

d. Ocorre a variação denominativa em inglês com duas ou mais unidades composta por nome de cor que expressa ou não a mesma realidade cromática, p.ex.,

Pomacanthus peixe-anjo-de-banda-amarela half moon angelfish, maculosus fish, Arabian

(Forsskål, angelfish, map 1775) angelfish, maculosus angel, yellow-blotch angelfish, yellow bar angel(fish), yellowband angelfish, blue moon angel

e. Ocorre a variação denominativa em inglês com a presença de itens formados por mais de um nome de cor, p.ex.,

Pomacentrus caeruleus Quoy \& Gaimard, 1825 donzela-azul

\begin{abstract}
yellow belly blue damsel,
\end{abstract} caerulean damselfish

f. Ocorre a variação denominativa com a ausência de itens formados por nomes de cor, p.ex.,

Vachellia

farnesiana

(L.) Wight \&

Arn.

\section{acácia-amarela}

needle bush, dead finish, mimosa wattle, mimosa bush, prickly mimosa bush, prickly Moses, north-west curara, sheep's briar, sponge wattle, thorny feather wattle, sweet acacia, wild briar, 
huisache, cassie, cascalotte, cassic, mealy wattle, popinac, sweet briar, Texas huisache

ii) Para espécies que apresentam variação denominativa em língua portuguesa, constatamos que:

a. Ocorre a variação denominativa em língua inglesa, com a presença de itens formados por nome de cor que expressa a mesma realidade cromática, p.ex.,

Stegastes variabilis donzela-amarela, yellow demoiselle, (Castelnau, 1855) donzelinha-amarela e cocoa damselfish, saberê-amarelo, anjo, demoiselle fish, twocará, castanheta, donzela, spot demoiselle, donzela-cacau

b. Ocorre a variação denominativa em língua inglesa com a presença de unidades formadas por nome de cor que expressa uma realidade cromática distinta, p.ex.,

$\begin{array}{lll}\begin{array}{l}\text { Gymnothorax } \\ \text { ocellatus Agassiz, } \\ 1831\end{array} & \begin{array}{l}\text { moreia-amarela, miroró, } \\ \text { moreia, moreia-pintada, }\end{array} & \begin{array}{l}\text { blackedge moray, } \\ \text { sand moray, } \\ \text { mutuca, mututuca, }\end{array} \\ & \text { Caribbean } \\ & \text { moreia-de-areia, amoreia, } & \text { ocellated moray, } \\ & \text { caramuru-de-areia, pinima, } & \\ & \text { moreia-de-pedra, moreia- } & \\ & \\ & \text { ocelada }\end{array}$

c. Ocorre a variação denominativa em inglês com a presença de unidades compostas por nomes de cor que expressam ou não a mesma realidade cromática e com unidades não compostas por nomes de cor, p.ex., 


$\begin{array}{lll}\begin{array}{l}\text { Xanthosoma } \\ \text { violaceum Schott }\end{array} & \begin{array}{l}\text { mangarito-roxo, arão, } \\ \text { aro, bezerro, jarro, }\end{array} & \begin{array}{l}\text { purple stemmed } \\ \text { elephant ear, } \\ \text { mangarito-grande, pé-de- }\end{array} \\ & \begin{array}{l}\text { purplestem taro, blue } \\ \text { bezerro, taiá, taiá-açu, } \\ \text { taiaúva, taiova, taioba, }\end{array} & \begin{array}{l}\text { taro, blue ape, blue } \\ \text { tajá, tajá-açu, tajabuçu, }\end{array} \\ & \text { talo, taro, tarro, orelha- } & \\ & \text { de-elefante } & \end{array}$

d. Ocorre variação denominativa em inglês sem a utilização do nome de cor, p.ex.,

Hemiramphus agulha-preta, ballyhoo, ballyhoo

brasiliensis agulhinha halfbeak, bally

(L., 1758)

e. Constatamos a correspondência única por meio de um item formado por um nome de cor que expressa a mesma realidade cromática, p.ex.,
Kajikia
marlim-branco, agulhão-
white marlin
albida (Poey, 1860)
branco, agulhão, agulhão-de-
prata, bicuda

f. Constatamos a correspondência única por meio de um item não formado por nome de cor, p.ex.,

Hyporhamphus agulha-branca, panaguaiú, common halfbeak

unifasciatus

(Ranzani, 1841)

peixe-agulha, tarangalho,

tarnagalho

g. Não há correspondentes, p.ex.,

Ocotea pulchella (Nees \& Mart.) Mez - canela-preta, canela-do-brejo, canelinha, canela-lageana 
iii) Para espécies que apresentam variação denominativa em português em que coocorrem itens formados por nomes de cores diferentes:

a. Ocorre em língua inglesa a variação denominativa com itens formados por um nome de cor que expressa uma mesma realidade cromática, p.ex.,

Acanthurus

coeruleus

Bloch \&

Schneider, 1801 cirurgião-azul, acaraúnaazul, sangrador-azul, peixecirurgião-azul, barbeiroamarelo, barbeiro-azul, barbeiro, lanceta, peixedoutor blue tang, blue caribbean tang, atlantic blue tang, blue tang surgeonfish

b. Ocorre em inglês a correspondência única por meio de um item formado por um nome de cor que expressa a mesma realidade cromática, p.ex.,
Pteroglossus
araçari-de-bico-branco,
black-necked aracari
aracari aracari-pescoço-preto,
(L., 1758)
araçari-da-mata, araçari-de-
minhoca, araçari-minhoca,
tucano-de-cinta, camisa-de-
meia, araçari-de-bico-marfim

c. Ocorre em inglês a correspondência única por meio de uma unidade não composta por nome de cor, p.ex.,

Nectandra

lanceolata Nees canela-amarela, canela-da-várzea, lanceolate canela-fedorenta, canela-louro, nectandra canela-vermelha, espora-de-galo

d. A correspondência em inglês se dá pela presença de variantes formadas ou não por nomes de cores, p.ex., 
Nectandra globosa canela-preta, cedro-preto, white silverballi, (Aubl.) Mez

loiro-vermelho, lourovermelho, siruabale, surineia globose nectandra, silverballi, sweetwood

e. Ocorre em inglês a variação denominativa por meio de unidades não formadas por nomes de cor, p.ex.,

Endlicheria paniculata canela-preta, canela- peniculate (Spreng.) Macbr branca, canela-amarela, endilcheria, canela-cheirosa, canela- canela tree do-brejo, canela-frade, canela-peluda

Assim como para a língua inglesa, se realizarmos uma análise comparativa entre a língua portuguesa e a língua italiana, considerando em português não apenas as ECEs, mas todas as variantes denominativas de cada espécie abordada no dicionário.

i) Para espécies popularmente denominadas em português por uma ECE:

a. A correspondência em italiano se dá por uma ECE formada por um nome de cor que expressa a mesma realidade cromática, p.ex.,

Euterpe oleracea var. branco açaí-branco açaí bianco

b. Ocorre em italiano a correspondência única sem a presença do nome de cor, p.ex.,

Mimosa arenosa (Willd.) Poir. jurema-vermelha sefora 
c. Ocorre em italiano a variação denominativa com a presença de uma unidade composta por um nome de cor que expressa a mesma realidade cromática, p.ex.,

Iguana iguana (L., 1758) iguana-verde iguana verde/iguana comune/iguana dai tubercoli

d. Ocorre em língua italiana a variação denominativa com a presença de uma unidade formada por um nome de cor que expressa uma realidade cromática diferente, p.ex.,

Chromis multilineata donzela-marrom castagnola nera, (Guichenot, 1853)

castagnola, guerracino

e. Ocorre em italiano a variação denominativa com mais de uma unidade composta por nomes de cor que expressam realidades cromáticas diferentes, p.ex.,

Amazona

brasiliensis

(L., 1758) papagaio-de-cara-roxa

amazzone codarossa, amazzone coda rossa, amazzonia a coda rossa

f. Ocorre em italiano a variação denominativa com a ausência de itens formados por nomes de cor, p.ex.,

Vachellia farnesiana acácia-amarela gaggìa, acacia (L.) Wight \& Arn.

ii) Para espécies que apresentam variação denominativa em língua portuguesa:

a. Ocorre em língua italiana a variação denominativa com item formado por nome de cor que expressa a mesma realidade cromática e com itens não compostos por nomes de cor, p.ex., 


$\begin{array}{lll}\text { Chiropotes satanas } & \text { cuxiú-preto, cuxiú- } & \text { saki dalla barba } \\ \text { satanas } & \text { negro, cuxiú-comum, } & \text { nera, chiropote } \\ \text { (Hoffmannsegg, 1807) } & \text { cuxiú-judeu } & \text { satanasso, scimmia } \\ & & \text { satanasso }\end{array}$

b. Ocorre a variação denominativa com item formado por nome de cor que expressa uma realidade cromática diferente, p.ex.,

Cebus xanthosternos macaco-prego-do- cebo testabruna, (Wied-Neuwied, peito-amarelo, cebo dal ventre dorato 1826) macaco-de-bando

c. Ocorre variação denominativa sem a utilização do nome de cor, p.ex.,

Caiman latirostris jacaré-do-papo-amarelo, caimano dal muso (Daudin, 1802) aruá, arurá, caimão, largo, alligatore ururau muso largo, caimano brasiliano

d. Constatamos em italiano a correspondência única com item formado por um nome de cor que expressa a mesma realidade cromática, p.ex.,

Kajikia albida marlim-branco, agulhão-branco, marlin bianco (Poey, 1860) agulhão, agulhão-de-prata, bicuda

e. Constatamos em italiano a correspondência única com item não formado por nome de cor, p.ex.,

Lithraea molleoides aroeira-branca, aroeira-brava, aruera (Vell.) Engl. aroeira-de-capoeira, aroeirinha, bugreiro, aroeira-do-brejo 
f. Não há correspondentes em língua italiana, p.ex., Ocotea pulchella (Nees \& Mart.) Mez - canela-preta, canela-do -brejo, canelinha, canela-lageana

iii) Para espécies que apresentam variação denominativa em português em que coocorrem itens formados por nomes de cores diferentes:

a. Ocorre em língua italiana a variação denominativa com unidades formadas por nomes de cores também distintos, p.ex.,

Thunnus thynnus atum-vermelho, atum-de- tonno rosso, (L., 1758) barbatana-azul, atum-azul, tonno pinna blu albacora-azul, atum-verdadeiro, atum-legítimo

b. Constatamos a correspondência única com item formado por um nome de cor que expressa a mesma realidade cromática, p.ex.,

Pteroglossus aracari araçari-de-bico-branco, aracari- aracari (L., 1758) pescoço-preto, araçari-da-mata, collonero araçari-de-minhoca, araçariminhoca, tucano-de-cinta, camisa-de-meia, araçari-debico-marfim

c. Constatamos em italiano a correspondência única por meio de um item não composto por nome de cor, p.ex.,

Peltogyne confertiflora pau-roxo, coataquiçauá, amaranto (Mart. ex Hayne) Benth. coataquiçava, coraci, quarabu, guarabu, mulateiro-da-terrafirme, pau-roxo-da-caatinga, 
pau-roxo-da-várzea, pau-roxoda-terra-firme, pau-violeta, violeta, roxinho

d. Ocorre em italiano a variação denominativa com unidades formadas ou não por nomes de cor, p.ex.,

Psidium cattleyanum araçá-vermelho, araçá-rosa, Sabine araçá-de-coroa, araçá-deguaiabo rosso, comer, araçá-comum, araçáda-praia, araçá-do-campo, araçá-do-mato, araçazeiro, araçá-amarelo, araçá

e. Não há correspondentes, p.ex., Cecropia hololeuca Miq. - embaúba-branca, embaúva-branca, embaúba-prateada, embaúva-preta, umbaúba-branca.

\section{Discussões}

De um modo geral, mostra-se evidente a discrepância numérica de variantes denominativas nas línguas em estudo, sendo mais frequente em língua portuguesa, seguida pela inglesa. Com efeito, dentre as 92 espécies da Fauna, apenas 12 não apresentaram correspondentes unicamente em língua italiana. Por outro lado, dentre as 75 espécies da Flora, 20 não apresentaram correspondentes em língua italiana e somente 10 não apresentaram em língua inglesa. A título de conclusão, gostaríamos de enumerar alguns pontos que merecem ser discutidos.

O primeiro deles diz respeito à ocorrência geográfica das espécies e sua influência na terminologia. De fato, uma grande parte das espécies catalogadas em nosso trabalho ou é nativa de um dos biomas compreendidos pelo território brasileiro, ou é originário da 
América do Sul, especificamente, do bioma amazônico. A partir dessa constatação, entende-se o grande número de variantes denominativas em língua portuguesa. Nesse aspecto, têm destaque as espécies da Flora, resultado de sua ocorrência ao longo do território brasileiro e consequente denominação por diferentes comunidades. Por conseguinte, explica-se o baixo número de variantes denominativas em língua italiana e também a ausência de correspondentes para um maior número de itens nessa língua. Claro, o distanciamento entre as realidades categorizadas por essas duas culturas faz com que a criação de variantes não aconteça ou até mesmo seja dispensável na língua em questão.

Por outro lado, temos o número reduzido de correspondência zero em língua inglesa, além da grande frequência de casos em que se verifica a variação denominativa. Uma justificação para tal fato seria o interesse científico em estudar as espécies da Fauna e da Flora por parte de alguns países de língua inglesa e consequente mobilidade de tais estudiosos para o ambiente natural das mesmas. Aliado a tal fator, temos a busca pela divulgação das pesquisas desenvolvidas no Brasil por meio da tradução de artigos científicos e, consequentemente, da tradução dos nomes populares em língua portuguesa para a língua inglesa.

No que concerne ao uso dos nomes de cores, observamos, na maior parte dos casos, a correspondência do subdomínio cromático utilizado entre as línguas portuguesa e inglesa, fato esse que pode estar relacionado ao status de língua franca desta última e à internacionalização da ciência. Assim, a correspondência entre os traços apreendidos e representados nas variantes denominativas também seria fruto da tradução desses itens a partir da língua portuguesa. Ainda no que concerne à língua inglesa, podemos afirmar que a frequência de correspondentes formados por nomes de cor é menor, sobretudo se considerarmos apenas os casos de correspondente único. Apesar disso, para os casos de múltiplos correspondentes, os grupos em que coexistem expressões compostas ou não por nomes de cores prevalecem. 
Outra constatação interessante diz respeito ao fato de as espécies da Fauna estarem mais propícias a receber uma ECE como correspondente do que as espécies da Flora. De fato, naquele domínio o item cor é utilizado juntamente com outras partes do animal na sua distinção, ressaltando suas particularidades. Desse modo, a variação do subdomínio cromático está relacionada à parte do corpo da espécie que mais salta aos olhos do observador. Por exemplo, araçari-de-bico-branco e araçari-pescoço-preto, duas partes diferentes, bico e pescoço, com cores diferentes. No domínio da Flora, essa discriminação é menos frequente.

Em suma, de um modo geral, buscamos demonstrar a forma como a variação denominativa ocorre no campo de estudo abordado e como ela pode estar relacionada a motivações que ultrapassam o nível da categorização dos conceitos, de modo a enfatizar a importância do exame do uso linguístico para a compreensão da dinâmica das línguas e culturas. Nesse sentido, o estudo comparativo da variação em terminologia e sua motivação demonstra as diferenças e semelhanças na percepção, na compreensão e na representação linguística dos conceitos pelo homem, bem como a complexidade que envolve tal processo.

Agradecimentos: Agradecemos à Profa. Dra. Claudia Zavaglia pela orientação do projeto de doutorado que derivou neste texto e à FAPESP (Proc. n. 2013/09232-1) pelo auxílio concedido.

\section{Referências}

ARCAINI, E. Analisi linguistica e traduzione. Bologna: Pàtron, 1991.

BERLIN, B.; KAY, P. Basic Color Terms: Their Universality and Evolution. Berkeley: University of California Press, 1969. 
BACH, C.; SUÁREZ, M. M. La variación denominativo-conceptual en la traducción científico-técnica: el papel de la reformulación. In: CHABÁS, J. et al. (Ed.). Translating Science: Proceedings: 2nd International Conference on Specialized Translation. Barcelona: PPU, 2002, p. 119-127.

BIDERMAN, M. T. C. O conhecimento, a terminologia e o dicionário. Ciência e Cultura, Campinas, v. 58, p. 35-37, 2006.

. Teoria linguística. 2. ed. São Paulo: Martins Fontes, 2001.

CABRÉ, M. T. El principio de poliedricidad: la articulación de lo discursivo, lo cognitivo y lo lingüístico en Terminología. Pt. 1. Ibérica, Castelló de la Plana, v. 16, p. 9-36, 2008a.

. La terminología en la traducción especializada. In: GONZALO GARCÍA, C.; GARCÍA YEBRA, V. (Ed.). Manual de documentación y terminología para la traducción especializada. Madrid: Arco/Libros, 2004, p. 89-125.

. La Terminologia: representación y comunicación: elementos para una teoría de base comunicativa y otros artículos. Barcelona: Universitat Pompeu Fabra, 1999.

. Análisis textual y terminología, factores de activación de la competencia cognitiva en la traducción. In: ALCINA CAUDET, A.; GAMERO PÉREZ, S. (Ed.). La traducción científico-técnica y la terminología en la sociedad de la información. Castellón de la Plana: Universitat Jaume I, 2002, p. 87-105.

CIAPUSCIO, G. E. Textos especializados y terminología. Barcelona: Institut Universitari de Linguística Aplicada, Universitat Pompeu Fabra, 2003.

FREIXA, J. Variación terminológica: ¿por qué y para qué? Meta: Journal des traducteurs, Montréal, v. 50, n. 4, 2005.

. La variació terminològica: anàlisi de la variació denominativa en textos

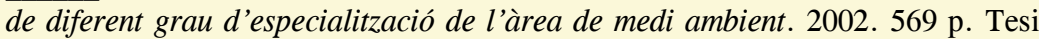
Doctoral (Doctorat en Variació en el Llenguatge)- Departament de Filologia Catalana, Universitat de Barcelona, Barcelona, 2002. Disponível em: < http:// www.tdx.cat/handle/10803/1677> . Acesso em: 20 Out. 2015. 
FREIXA, J.; KOSTINA, I. CABRÉ, M. T. La variación terminológica en las aplicaciones terminográficas. In: SIMPOSIO IBEROAMERICANO DE TERMINOLOGÍA, 8., 2002, Cartagena de Indias. Actas. Cartagena de Indias: [s.n.], 2002. 1 CD-ROM.

GARRIDO, C. Traducción de los nombres vernáculos ingleses de animales en los textos de divulgación científica. In. BEEBY, A.; ENSINGER, D.; PRESAL, M. Investigating Translation. Amsterdam: J. Benjamins, 2000, p. 251-260.

MARTINS, S. C.; ZAVAGLIA, C. Dicionários especiais: uma ponte para divulgação e transmissão dos saberes. In: Groupe de Linguistique Appliquée des Télécommunications (GLAT). Gênova: GLAT-Genova, 2012, p. 309-319.

SILVA FILHO, S. C. A variação e a relação conceito/termo: uma questão de ponto de vista. Revista Trama, Marechal Cândido Rondon, v. 6, n. 12, p. 7586, 2010a. Disponível em: < http://e-revista.unioeste.br/index.php/trama/article/ view/5121/3828 > . Acesso em: 10 Maio 2014.

ZAVAGLIA, C. Dicionário e cores. Alfa, São Paulo, v. 50, n. 2, p. 25-41, 2006.

. Os cromônimos no italiano e no português do Brasil: uma análise comparativa. 1996. 264 p. Dissertação (Mestrado em Língua e Literatura Italiana)-Faculdade de Filosofia, Letras e Ciências Humanas, Universidade de São Paulo, São Paulo, 1996.

Recebido em: 03 de dezembro de 2017

Aceito em: 05 de março de 2018

Publicado em: maio de 2018

Sabrina de Cássia Martins. E-mail: sabrismartins@gmail.com 